\title{
Effects of an Educational Intervention of Physical Activity for Children and Adolescents With Cystic Fibrosis: A Randomized Controlled Trial
}

\author{
Patrícia Xavier Hommerding PhD, Rafael R Baptista PhD, Gabriel T Makarewicz, \\ Cláudia S Schindel, Márcio VF Donadio PhD, Leonardo A Pinto PhD, and \\ Paulo JC Marostica PhD
}

\begin{abstract}
BACKGROUND: Regular aerobic exercise in patients with cystic fibrosis (CF) improves aerobic conditioning and delays disease progression, resulting in better quality of life. The purpose of this study was to evaluate the effect of an aerobic exercise program based on verbal and written guidelines on maximum exercise capacity using a cardiopulmonary exercise test, quality of life, and the self-reported aerobic exercise practice of children and adolescents with CF. METHODS: This randomized controlled trial followed guidelines for physical exercise in a CF center. Subjects were assigned to 2 groups: intervention (group 1), with 17 subjects; and control (group 2), also with 17 subjects. Data were collected from October 2010 to October 2011, and the study population comprised 7-20-y-old children and adolescents with CF. The intervention consisted of handing out a manual with guidelines for aerobic physical exercises and reinforcing recommendations in telephone calls every 2 weeks. RESULTS: Thirty-four subjects were included in the study, 20 of whom were boys $(58.5 \%)$. The groups were similar at baseline. In group 1,6 subjects $(35.2 \%)$ reported practicing physical exercises regularly. The mean age was $13.4 \pm 2.8 \mathrm{y}$, the mean percent-ofpredicted $\mathrm{FEV}_{1}$ was $95.5 \pm 17.9 \%$, and the mean peak oxygen uptake $\left(\dot{\mathrm{V}}_{\mathrm{O}_{2}}\right)$ relative to body mass was $34.9 \pm 9.0 \mathrm{~mL} / \mathrm{kg} / \mathrm{min}$. In group 2,4 subjects $(23.5 \%)$ reported practicing physical exercises regularly. The mean age was $12.7 \pm 3.3 \mathrm{y}$, the mean percent-of-predicted $F E V_{1}$ was $100.1 \pm 21.2 \%$, and the mean peak $\dot{V}_{O}$, was $33.2 \pm 8.2 \mathrm{~mL} / \mathrm{kg} / \mathrm{min}$. In group 1, there was a significant increase in physical exercise practice as reported by subjects after 3 months of intervention compared with group $2(P=.01)$. No statistically significant differences were found for the other variables. CONCLUSIONS: Verbal and written guidelines for aerobic exercise, together with supervision over the telephone, had a positive impact on the self-reported regular physical exercise practice of children and adolescents. However, no improvement was found in lung function and maximum exercise capacity or domains of the quality of life questionnaire. Key words: cystic fibrosis; aerobic exercise; maximal exercise test; quality of life; children; adolescents. [Respir Care 2015;60(1):81-87. (C) 2015 Daedalus Enterprises]
\end{abstract}

\section{Introduction}

Regular aerobic exercise in childhood and adolescence has important benefits for the biological process

\footnotetext{
Dr Hommerding is affiliated with the Faculdade de Fisioterapia, Centro Universitario Franciscano (UNIFRA), Santa Maria, Rio Grande do Sul, Brazil. Dr Baptista is affiliated with Faculdade de Educação Física e Ciencias do desporto, Pontificia Universidade Catolica do Rio Grande do Sul, Porto Alegre, Rio Grande do Sul, Brazil. Ms Makarewicz and Ms Schindel are affiliated with the Pontificia Universidade Catolica do Rio
}

of growth and human development. ${ }^{1}$ Children and adolescents with cystic fibrosis (CF) who practice regular

\footnotetext{
Grande do Sul, Porto Alegre, Rio Grande do Sul, Brazil. Dr Pinto is affiliated with Faculdade de Medicina, Pontificia Universidade Catolica do Rio Grande do Sul, Porto Alegre, Rio Grande do Sul, Brazil. Dr Donadio is affiliated with the Faculdade de Enfermagem, Nutrição e Fisioterapia, Pontifícia Universidade Católica do Rio Grande do Sul, Porto Alegre, Rio Grande do Sul, Brazil. Dr Marostica is affiliated with the Faculdade de Medicina, Universidade Federal do Rio Grande do Sul (UFRGS), Porto Alegre, Rio Grande do Sul, Brazil.
} 
physical activities have better aerobic conditioning, greater nutritional status stability, and significantly delayed disease progression. ${ }^{2,3}$

In the assessment of the maximum exercise capacity of patients with $\mathrm{CF}$, ergospirometry may be used to evaluate, in a global and integrated way, the respiratory, cardiovascular, neuromuscular, and metabolic systems, and the measurement of maximum oxygen uptake $\left(\dot{\mathrm{V}}_{\mathrm{O}_{2}}\right)$ has been widely used in the literature as one of the main markers of the capacity to perform exercises of long duration. ${ }^{4,5}$

As one of the approaches to the treatment of these patients, the effect of aerobic exercise on the life of children and adolescents with $\mathrm{CF}$ has been investigated in several studies, and results suggest that regular exercise and adherence to a physical exercise program are fundamental. ${ }^{6-8}$ Some recommendations for the exercise practice have been developed and reviewed along the years to help individuals and health-care professionals to initiate appropriate preventive or therapeutic programs. ${ }^{9,10}$

However, few properly designed, randomized studies have been conducted to evaluate whether guidelines prepared by health-care professionals as recommendations of physical exercises, modality, frequency, intensity, and stretching are effective and regularly adopted by patients. ${ }^{11,12}$ The purpose of this study was to evaluate the effect of an aerobic exercise program based on verbal and written guidelines on maximum exercise capacity using a cardiopulmonary exercise test, quality of life, and the selfreported aerobic exercise practice of children and adolescents with $\mathrm{CF}$.

\section{Methods}

This randomized controlled trial followed guidelines for physical exercise in the Cystic Fibrosis Outpatient Clinic of Hospital São Lucas, Pontifícia Universidade Católica do Rio Grande do Sul, Porto Alegre, Rio Grande do Sul, Brazil. The study followed the recommendations of Consolidated Standards of Reporting Trials and was registered at Registro Brasileiro de Ensaios Clínicos (UTN U11111123-4083). The study was approved by the Ethics in Research Committee of Pontifícia Universidade Católica do Rio Grande do Sul, and all subjects or their guardians (when $<18$ y old) signed a written consent form.

\footnotetext{
The authors have disclosed no conflicts of interest.
}

Correspondence: Patrícia Xavier Hommerding PhD, Faculdade de Fisioterapia, Centro Universitario Franciscano (UNIFRA), Santa Maria, Rio Grande do Sul 97010-032, Brazil. E-mail: patixh@yahoo.com.br.

DOI: $10.4187 /$ respcare. 02578

\section{QUICK LOOK}

\section{Current knowledge}

Pulmonary rehabilitation including aerobic exercise and strength training in patients with cystic fibrosis may improve quality of life and delay disease progression. Few guidelines for design of these exercise programs have been published with respect to the frequency and intensity of exercise.

\section{What this paper contributes to our knowledge}

In a small group of adolescents with cystic fibrosis, verbal and written guidelines for aerobic exercise, together with supervision over the phone, had a positive impact on the report of regular physical exercise practice. No improvement was found in lung function and maximum exercise capacity or domains of the quality of life questionnaire.

Data were collected from October 2010 to October 2011. Children and adolescents were included in the study if they were 7-20 y old, their disease was stable, and they had no signs of exacerbation of respiratory symptoms in the last 15 d. ${ }^{13}$ Exclusion criteria were cognitive impairments that made test performance impossible, non-CFrelated bone and muscle abnormalities, and heart disease with hemodynamic instability.

\section{Sample}

For a difference of 18.1 points in the physical score of the quality of life questionnaire and an SD of 13.8 points, the sample size was estimated as 15 subjects for each group to detect efficacy of exercise guidelines at a power of $95 \%$ and a level of significance of $5 \%$. The total sample size was 30 subjects with CF. Two more subjects were included in each group because of possible losses, so the total was 34 subjects. Calculations were based on the difference of the physical score in the quality of life questionnaire between groups in a study conducted by Klijn et al. ${ }^{14}$

\section{Protocol}

A computer-based program was used for randomization (Random Allocation Software 1.0, developed by M. Saghaei MD, Department of Anesthesia, University of Medical Sciences, Isfahan, Iran) by blocks of 6 subjects, who were assigned to one of 2 groups: intervention (group 1) and control (group 2). Subjects randomly assigned to group 1 received a manual of aerobic physical 
exercises, such as jogging, swimming, walking, dancing, playing ball games, skipping rope, and others in which they might be interested, as well as instructions for stretching the upper extremities, trunk, and lower extremities after the correct stretching technique was demonstrated. An illustrated manual was provided that included figures demonstrating stretches and a monthly calendar in which the subject was to record when aerobic exercise was performed. There were no recommendations for exercise intensity.

The subjects were told to practice the exercise modality that they preferred and that was available to them at a minimum frequency of 2 times/week for at least $20 \mathrm{~min}$ and to record in the calendar the days of the month and the frequency, duration, and type of physical exercise performed. Subjects in group 1 received telephone calls from one of the authors (PXH) every 2 weeks, and aerobic exercise practice was reinforced, questions were answered, and recommendations were made. A self-report was collected during the telephone calls. When talking to the subject or subject's guardian, the author made notes about the report on exercise practice, regularity, and interest to control and evaluate the progression during the 3 -month follow-up. In group 2, the subjects were instructed verbally about aerobic exercise only on the day that they were included in the study, according to the CF center routine.

There were 2 assessments: the first month and then 3 months later. Both groups 1 and 2 underwent respiratory function tests (spirometry), anthropometric evaluations, and maximal exercise tests (ergospirometry), and the quality of life questionnaire for CF was applied.

\section{Spirometry}

Spirometry was conducted by a trained resident using a KoKo spirometer (Ferraris Medical, Louisville, Colorado). Data evaluated were FVC, $\mathrm{FEV}_{1}$, Tiffeneau index $\left(\mathrm{FEV}_{1} / \mathrm{FVC}\right)$, and the forced expiratory flow at $25-75 \%$ of the FVC. Absolute values were measured, and the predicted percentages for sex, age, and height were calculated. ${ }^{15}$

\section{Anthropometric Evaluation}

Body mass was measured while the subject was wearing light clothes and no shoes using a platform beam scale (Filizola, São Paulo, Brazil) that measures up to $180 \mathrm{~kg}$ to the nearest $100 \mathrm{~g}$. Height was measured using a wall stadiometer (Sanny, São Bernardo do Campo, Brazil). Body mass index was calculated using the 2007 WHO AnthroPlus software. ${ }^{16}$

Triceps skin fold thickness was measured using a skin fold caliper (Cescorf, Porto Alegre, Rio Grande do Sul,
Brazil) that applies a pressure of $10 \mathrm{~g} / \mathrm{mm}^{2}$ and readings to the nearest $1 \mathrm{~mm}$. To evaluate muscle reserve, the arm muscle circumference was calculated according to brachial circumference and triceps skin fold thickness. The values were normalized according to Frisancho percentiles. ${ }^{17}$

\section{Quality of Life Questionnaire}

The Cystic Fibrosis Questionnaire for quality of life has 3 versions according to age groups: $6-11 \mathrm{y}, 12-13 \mathrm{y}$, and $\geq 14 \mathrm{y}$. The following domains were evaluated: physical, body image, digestive, respiratory, emotional, social, nutrition, treatment, vitality, health, social role, and weight. For children 6-11 y old, the instrument was applied by one of the authors (GTM), who was trained for the task. The other questionnaires were filled out by the subjects according to the Cystic Fibrosis Questionnaire instructions. ${ }^{18}$ Scores for each domain ranged from 0 to 100 . A score of 100 was classified as very good quality of life, and scores above 50 were classified as good quality of life.

\section{Ergospirometry}

Gas uptake was measured using an ergospirometry system with a VO2000 gas analyzer (Medical Graphics, St Paul, Minnesota), which provides information about ventilation every $20 \mathrm{~s}$. A nose clip was used, and a small or medium mouthpiece was placed over the child's mouth and adjusted to avoid leaks around it. This mouthpiece system was connected to a previously calibrated electronic device that allowed the passage of gases during exhalation. The test was conducted by one of the authors (GTM), who was previously trained, and followed the recommendations of the American College of Sports Medicine. ${ }^{19}$

The ramp protocol was prepared for progressive intensity, beginning at $4 \mathrm{~km} / \mathrm{h}$ and increasing half kilometer per hour at every minute until voluntary exhaustion of the subject. Data were recorded and sent to AeroGraph Software (Medical Graphics Corporation. St. Paul, Minnesota) for later analysis (peak $\dot{\mathrm{V}}_{\mathrm{O}_{2}}$ and maximum heart rate).

Heart rate and $\mathrm{S}_{\mathrm{pO}_{2}}$ were measured at rest and every $60 \mathrm{~s}$ until completion of the test using a portable pulse oximeter (Nonin, Plymouth, Minnesota); the subjective perception of dyspnea intensity and fatigue of lower extremities was assessed using a modified Borg scale quantified 0-10, where 0 represents no symptoms and 10 represents maximum symptoms, with 5 representing intense activity.

Blood pressure was measured using a sphygmomanometer (Bic Med, Itupeva, Brazil) at rest and at the end of the test, which was interrupted only when the subjects signaled using a previously defined gesture for fatigue or any discomfort. 
Table 1. General Characteristics of the Intervention and Control Groups

\begin{tabular}{|c|c|c|c|}
\hline Variable & $\begin{array}{c}\text { Group } 1 \\
\text { (Intervention, } n=17 \text { ) }\end{array}$ & $\begin{array}{c}\text { Group 2 } \\
\text { (Control, } n=17)\end{array}$ & $P$ \\
\hline Age (mean $\pm \mathrm{SD}), \mathrm{y}$ & $13.4 \pm 2.8$ & $12.7 \pm 3.3$ & .55 \\
\hline Boys, $n(\%)$ & $10(58.8)$ & $10(58.8)$ & $>.99$ \\
\hline Weight (mean $\pm \mathrm{SD}), \mathrm{kg}$ & $46.1 \pm 14.0$ & $45.0 \pm 16.6$ & .84 \\
\hline Height (mean \pm SD), m & $1.5 \pm 0.1$ & $1.4 \pm 0.1$ & .23 \\
\hline Regular physical activity, $n(\%)$ & $6(35.2)$ & $4(23.5)$ & .46 \\
\hline $\mathrm{FEV}_{1}($ mean $\pm \mathrm{SD}), \%$ predicted & $95.5 \pm 17.9$ & $100.1 \pm 21.2$ & .50 \\
\hline FVC $($ mean $\pm \mathrm{SD}), \%$ predicted & $106.4 \pm 15.2$ & $107.7 \pm 21.1$ & .71 \\
\hline $\mathrm{FEV}_{1} / \mathrm{FVC}($ mean $\pm \mathrm{SD})$ & $0.81 \pm 0.09$ & $0.81 \pm 0.08$ & .70 \\
\hline $\mathrm{FEF}_{25-75 \%}($ mean $\pm \mathrm{SD})$ & $78.7 \pm 28.5$ & $72.8 \pm 31.3$ & .71 \\
\hline $\mathrm{S}_{\mathrm{pO}_{2}}$ at rest (mean $\left.\pm \mathrm{SD}\right), \%$ & $96.2 \pm 0.9$ & $96.3 \pm 2.3$ & .92 \\
\hline Peak $\dot{\mathrm{V}}_{\mathrm{O}_{2}}($ mean $\pm \mathrm{SD}), \mathrm{mL} / \mathrm{kg} / \mathrm{min}$ & $34.9 \pm 9.0$ & $33.2 \pm 8.2$ & .58 \\
\hline Treadmill time (mean $\pm \mathrm{SD})$, min & $11.1 \pm 4.6$ & $9.8 \pm 2.8$ & .27 \\
\hline Speed (mean $\pm \mathrm{SD}), \mathrm{km} / \mathrm{h}$ & $8.9 \pm 2.2$ & $8.2 \pm 1.5$ & .27 \\
\hline Maximum heart rate (mean $\pm \mathrm{SD}$ ), beats/min & $157.1 \pm 38.5$ & $167.7 \pm 20.8$ & .40 \\
\hline BMI z-score (mean $\pm \mathrm{SD})$ & $-0.05 \pm 1.0$ & $0.4 \pm 1.1$ & .19 \\
\hline Triceps skin fold (mean $\pm \mathrm{SD}$ ), $\mathrm{g} / \mathrm{mm}^{2}$ & $9.6 \pm 5.4$ & $12.2 \pm 6.6$ & .21 \\
\hline Arm muscle circumference (mean $\pm \mathrm{SD}$ ), $\mathrm{cm}$ & $18.9 \pm 3.0$ & $18.7 \pm 3.4$ & .83 \\
\hline $\begin{array}{l}\mathrm{FEF}_{25-75 \%}=\text { forced expiratory flow at } 25-75 \% \text { of the } \mathrm{FVC} \\
\mathrm{V}_{\mathrm{O}_{2}}=\text { oxygen uptake } \\
\mathrm{BMI}=\text { body mass index }\end{array}$ & & & \\
\hline
\end{tabular}

\section{Statistical Analysis}

Results were described as mean $\pm \mathrm{SD}$ or median and interquartile range. The chi-square test was used to compare categorical variables, the Student $t$ test for independent samples was used for comparisons of continuous variables with normal distribution between the 2 groups, and the Mann-Whitney $U$ test was used for the comparison of ordinal variables or non-normally distributed continuous variables. The level of significance was set at $P<.05$. Data analyses were conducted using PASW 17.0.2 (Predictive Analytics Software, Somers, New York).

\section{Results}

Thirty-four subjects with CF were included in the study, 20 of whom were boys $(58.5 \%)$. Eleven subjects reported practicing physical exercises regularly. The mean age was $13.0 \pm 3.0 \mathrm{y}$, the mean percent-of-predicted $\mathrm{FEV}_{1}$ was $95.1 \pm 18.1 \%$, and the mean peak $\dot{\mathrm{V}}_{\mathrm{O}_{2}}$ was $34.1 \pm 8.4 \mathrm{~mL} / \mathrm{kg} / \mathrm{min}$. Seventeen subjects were randomly assigned to the intervention group (group 1), and 17 were assigned to the control group (group 2). Table 1 shows the comparison at baseline of general characteristics between the groups, and Table 2 shows the comparison of the quality of life domains in the Cystic Fibrosis Questionnaire at baseline. There were no significant differences between the 2 groups at baseline.
Table 2. Comparison of the Domains of the Cystic Fibrosis Questionnaire of Quality of Life Between the Intervention and Control Groups at Baseline

\begin{tabular}{lccc}
\hline \hline \multicolumn{1}{c}{ Domain } & $\begin{array}{c}\text { Group } 1 \\
\text { (Intervention, } n=17)\end{array}$ & $\begin{array}{c}\text { Group 2 } \\
\text { Control, } n=17)\end{array}$ & $P$ \\
\hline Physical* & $0(0-0)$ & $0(0-13)$ & .65 \\
Emotional & $0(0-6)$ & $0(8-0)$ & .10 \\
Social & $0(7-2)$ & $0(1-9)$ & .38 \\
Body image* & $0(0-5)$ & $5(0-22)$ & .41 \\
Nutrition* & $0(0-0)$ & $0(16-0)$ & .48 \\
Treatment* & $0(0-0)$ & $0(16-0)$ & .65 \\
Respiratory* & $0(-8-0)$ & $0(10-4)$ & .81 \\
Digestive* & $0(0-0)$ & $0(0-8)$ & .28 \\
Social Role $\dagger$ & $0(0-0)$ & $0(6-25)$ & .82 \\
Vitality $\dagger$ & $8(16-0)$ & $4(14-22)$ & .28 \\
Health $\dagger$ & $0(44-0)$ & $0(11-11)$ & .69 \\
Weight $\dagger$ & $0(66-0)$ & & .26 \\
& & & \\
Values are expressed as median (interquartile range). & & \\
$*$ Domains for all subjects & & & \\
$\dagger$ Domains only for subjects older than 14y & & \\
\hline
\end{tabular}

After 3 months, there was a significant increase in physical exercise practice reported by subjects in group $1 \mathrm{com}-$ pared with subjects in group $2(P=.01)$. There were no significant differences in the other clinical and physiological variables or quality of life domains between groups 1 and 2 at the 3-month follow-up (Table 3). Table 4 reports within-group changes to clarify that there were no significant changes in both of the groups after the intervention. 
Table 3. Comparison of Variations Between the Intervention and Control Groups at the 3-Month Follow-up

\begin{tabular}{|c|c|c|c|}
\hline Variable & $\begin{array}{c}\text { Group } 1 \\
\text { (Intervention, } n=17 \text { ) }\end{array}$ & $\begin{array}{c}\text { Group } 2 \\
\text { (Control, } n=17)\end{array}$ & $P$ \\
\hline$\Delta \mathrm{FEV}_{1}($ mean $\pm \mathrm{SD}), \%$ predicted & $-1.8 \pm 8.6$ & $1.0 \pm 14.2$ & .40 \\
\hline$\Delta \mathrm{FVC}($ mean $\pm \mathrm{SD}), \%$ predicted & $-0.4 \pm 6.7$ & $2.0 \pm 12.2$ & .48 \\
\hline$\Delta \mathrm{FEV}_{1} / \mathrm{FVC}($ mean $\pm \mathrm{SD}), \%$ predicted & $-0.4 \pm 7.7$ & $1.0 \pm 13.2$ & .48 \\
\hline$\Delta \mathrm{FEF}_{25-75 \%}($ mean $\pm \mathrm{SD}), \%$ predicted & $-3.8 \pm 13.8$ & $5.2 \pm 26.7$ & .22 \\
\hline$\Delta$ Regular physical activity, $n(\%)$ & $11(64.7)$ & $3(17.6)$ & .01 \\
\hline$\Delta \dot{\mathrm{V}}_{\mathrm{O}_{2}}$ peak $($ mean $\pm \mathrm{SD}), \mathrm{mL} / \mathrm{kg} / \mathrm{min}$ & $1.1 \pm 4.6$ & $2.3 \pm 11.9$ & .69 \\
\hline$\Delta$ Treadmill time (mean $\pm \mathrm{SD}$ ), $\min$ & $-0.3 \pm 1.7$ & $0.2 \pm 2.8$ & .91 \\
\hline$\Delta$ Speed $($ mean $\pm \mathrm{SD}), \mathrm{km} / \mathrm{h}$ & $-0.5 \pm 2.6$ & $0.1 \pm 1.5$ & .38 \\
\hline$\Delta \mathrm{S}_{\mathrm{pO}_{2}}$ at rest (mean $\left.\pm \mathrm{SD}\right), \%$ & $0.2 \pm 1.1$ & $0.9 \pm 3.7$ & $>.99$ \\
\hline$\Delta$ Final $\mathrm{S}_{\mathrm{pO}_{2}}($ mean $\pm \mathrm{SD}), \%$ & $-1.0 \pm 2.9$ & $-10.6 \pm 31.0$ & .72 \\
\hline$\Delta \mathrm{S}_{\mathrm{pO}_{2}}$ recovery $($ mean $\pm \mathrm{SD}), \%$ & $-6.2 \pm 22.0$ & $-12.4 \pm 32.1$ & .08 \\
\hline$\Delta$ Heart rate at rest (mean $\pm \mathrm{SD}$ ), beats $/ \mathrm{min}$ & $3.0 \pm 20.4$ & $-4.0 \pm 16.1$ & .27 \\
\hline$\Delta$ Final heart rate (mean $\pm \mathrm{SD}$ ), beats/min & $4.4 \pm 31.5$ & $-8.5 \pm 29.6$ & .22 \\
\hline$\Delta$ Maximum heart rate (mean $\pm \mathrm{SD}$ ), beats/min & $10.5 \pm 37.8$ & $-6.5 \pm 23.0$ & .12 \\
\hline \multicolumn{4}{|l|}{$\Delta$ Borg scale, median (interquartile range) } \\
\hline Final dyspnea & $0(-1-3)$ & $0(0-3)$ & .72 \\
\hline Dyspnea at recovery & $0(-2-1)$ & $0(0-4)$ & .08 \\
\hline Final fatigue & $0(-3-2)$ & $0(0-1)$ & .75 \\
\hline Fatigue at recovery & $0(-1-1)$ & $0(-1-2)$ & .75 \\
\hline$\Delta \mathrm{BMI}$ z-score $($ mean $\pm \mathrm{SD})$ & $0.2 \pm 0.5$ & $0.1 \pm 0.2$ & .46 \\
\hline$\Delta$ Triceps skin fold (mean $\pm \mathrm{SD}$ ), $\mathrm{g} / \mathrm{mm}^{2}$ & $0.3 \pm 1.3$ & $-0.09 \pm 1.0$ & .67 \\
\hline$\Delta$ Arm muscle circumference (mean $\pm \mathrm{SD}$ ), $\mathrm{cm}$ & $0.06 \pm 0.4$ & $-0.1 \pm 0.2$ & .98 \\
\hline \multicolumn{4}{|l|}{$\begin{array}{l}\mathrm{FEF}_{25-75 \%}=\text { forced expiratory flow at } 25-75 \% \text { of the FVC } \\
\dot{\mathrm{V}}_{\mathrm{O}_{2}}=\text { oxygen uptake } \\
\mathrm{BMI}=\text { body mass index }\end{array}$} \\
\hline
\end{tabular}

Table 4. Comparison of Exercise Changes in the Intervention and Control Groups

\begin{tabular}{lccc}
\hline \hline \multicolumn{1}{c}{ Variable } & $\begin{array}{c}\text { Group 1 } \\
\text { (Intervention, } n=17)\end{array}$ & $\begin{array}{c}\text { Group 2 } \\
\text { (Control, } n=17)\end{array}$ & $P$ \\
\hline Regular physical activity & $11(64.7)$ & $3(17.6)$ & .01 \\
Frequency (3 times/week) & $6(35.2)$ & $4(23.5)$ & .46 \\
Duration (at least 40 min) & $4(23.5)$ & $4(23.5)$ & .46 \\
Type of physical exercise & $11(64.7)$ & $4(23.5)$ & .01 \\
$\quad$ jogging, swimming, & & & \\
$\quad$ walking, dancing, & & & \\
$\quad$ playing ball games) & & $3(17.6)$ & .42 \\
Jogging & $4(23.5)$ & $4(23.5)$ & .46 \\
Swimming & $4(23.5)$ & $4(23.5)$ & .46 \\
Walking & $4(23.5)$ & $4(24.5)$ & .42 \\
Dancing & $3(17.6)$ & $3(17.6)$ & .34 \\
Playing ball games & $3(17.6)$ & $4(23.5)$ & .46 \\
Others modalities & $6(35.2)$ & &
\end{tabular}

Values are expressed as $n(\%)$

\section{Discussion}

This randomized controlled trial demonstrated that verbal and written guidelines for aerobic exercise, to- gether with telephone supervision, increased the reported physical exercise practice of the children and adolescents in group 1 after the 3-month follow-up. However, no improvement was found in lung function and maximum exercise capacity, such as $\mathrm{FEV}_{1}, \mathrm{FVC}$, or peak $\dot{\mathrm{V}}_{\mathrm{O}_{2}}$, or in the domains of the quality of life questionnaire.

Orenstein et $\mathrm{al}^{6}$ conducted a randomized trial with 67 CF subjects $8-18$ y of age who were assigned to an aerobic exercise group or to an upper-body strength-training regimen. Their program was supervised, and the subjects were re-evaluated after 6 months and $1 \mathrm{y}$. They found that both groups had an increase in muscle strength and tolerance to physical exercise. ${ }^{6}$ In our study, the intervention time before re-evaluation was 3 months, and this may be the reason why we did not detect differences in the parameters that measure adaptation to aerobic exercise. Another reason for the absence of improvement in exercise capacity and quality of life after the intervention could be the insufficient frequency of exercise and the lack of a guideline for training intensity.

Hebestreit et $\mathrm{al}^{20}$ evaluated the effects of a supervised and controlled conditioning program for subjects with CF. The primary outcome was maximum $\dot{\mathrm{V}}_{\mathrm{O}_{2}}$ after 6 months, and secondary outcomes were lung function, anthropo- 
metric data, and a quality of life questionnaire at 18 and 24 months after the beginning of the program. They found positive effects of the intervention on maximum $\dot{\mathrm{V}}_{\mathrm{O}_{2}}$, lung function (percent-of-predicted $\mathrm{FVC}$ ), and quality of life. ${ }^{20}$ However, during follow-up in our study, there were no significant differences in lung function (percent-ofpredicted $\mathrm{FEV}_{1}$ ) and no changes in the results of the quality of life questionnaire. The intervention duration may have been insufficient to improve the quality of life of the subjects; longer conditioning programs seem to be necessary.

Swisher and Erickson ${ }^{21}$ evaluated the perception of the importance of aerobic exercise in a group of adolescents with $\mathrm{CF}$ using semistructured telephone interviews and found that the subjects agreed about the importance of exercise for their treatment and quality of life. Some practiced sports regularly, but others reported not being interested, not having regular physical activities, and being unsure about the risk of disease exacerbation, often related to respiratory events, such as increasing cough or shortness of breath. ${ }^{21}$ In our study, there were no questions about the perception of the importance of exercise, and 6 $(35.2 \%)$ of the 17 subjects in the intervention group reported not adhering to physical exercise practice. Although we did not obtain findings similar to those reported by Swisher and Erickson, ${ }^{21}$ cough and shortness of breath are common symptoms in $\mathrm{CF}$ and might have resulted in the low adherence rates.

After 3 months of intervention, there was a significant increase in physical exercise practice reported by subjects in group 1 compared with subjects in group $2(P=.01)$. This effect on the practice of physical exercises might have been biased and might have resulted in higher numbers because the subjects knew they were supervised with telephone follow-ups and that they had to demonstrate and confirm the regular practice of aerobic exercises. The self-report bias is one of the limitations of randomized trials that could be overcome by asking detailed information about the exercise performed. In this study, we tried to overcome such a bias by specifically asking about the frequency, duration, and type of physical exercise performed.

Analysis of the maximal exercise test revealed that its early discontinuation and the level of tolerance to exercise in children and adolescents may result from lack of motivational factors, less concentration, inadequate subjective evaluation of dyspnea, and fatigue of lower extremities, which may explain the fact that maximum $\dot{\mathrm{V}}_{\mathrm{O}_{2}}$ was not obtained, as many subjects did not reach a maximum $\dot{\mathrm{V}}_{\mathrm{O}_{2}}$ plateau. Therefore, we decided to report the peak $\dot{\mathrm{V}}_{\mathrm{O}_{2}}$ values.

Our study did not find any peak $\dot{\mathrm{V}}_{\mathrm{O}_{2}}$ improvement after the intervention $(P>.05)$. Most subjects included in the study did not practice regular physical exercises at baseline. Moreover, many had little tolerance to the test per- formance and little response to the motivation received, which favored the early discontinuation of the test due to the factors mentioned above.

Although of a small magnitude, our findings indicate that the participation of subjects in a program that considers their preferences and accessibility to aerobic activities may increase their interest and motivation to practice exercises. A similar but longer or more intense intervention might improve patients' perception of the importance of such practice and improve their self-esteem and consequently their quality of life, in addition to physiologic parameters.

In conclusion, this study demonstrated that verbal and written guidelines for aerobic exercise resulted in an increase in self-reported aerobic exercise by children and adolescents. However, no improvement was found in lung function and maximum exercise capacity or in the domains of the quality of life questionnaire. Further studies using more intensive and longer interventions, paper calendars, and telephone calls should be conducted to elucidate this matter.

\section{REFERENCES}

1. Strong WB, Malina RM, Blimkie CJ, Daniels SR, Dishman RK, Gutin B, et al. Evidence based physical activity for school-age youth. J Pediatr 2005;146(6):732-737.

2. Selvadurai HC, Blimkie CJ, Meyers N, Mellis CM, Cooper PJ, Van Asperen PP. Randomized controlled study of in-hospital exercise training programs in children with cystic fibrosis. Pediatr Pulmonol 2002;33(3):194-200.

3. Nixon PA, Orenstein DM, Kelsey SF. Habitual physical activity in children and adolescents with cystic fibrosis. Med Sci Sports Exerc 2001;33(1):30-35.

4. ERS Task Force, Palange P, Ward SA, Carlsen KH, Casaburi R, Gallagher CG, et al. Recommendations on the use of exercise testing in clinical practice. Eur Respir J 2007;29(1):185-209.

5. Ferrazza AM, Martolini D, Valli G, Palange P. Cardiopulmonary exercise testing in the functional and prognostic evaluation of patients with pulmonary diseases. Respiration 2009;77(1):3-17.

6. Orenstein DM, Hovell MF, Mulvihill M, Keating KK, Hofstetter CR, Kelsey S, et al. Strength vs aerobic training in children with cystic fibrosis: a randomized controlled trial. Chest 2004;126(4):1204-1214.

7. Sexauer WP, Cheng HK, Fiel SB. Utility of the breathing reserve index at the anaerobic threshold in determining ventilatory-limited exercise in adult cystic fibrosis patients. Chest 2003;124(4):14691475.

8. Shah AR, Gozal D, Keens TG. Determinants of aerobic and anaerobic exercise performance in cystic fibrosis. Am J Respir Crit Care Med 1998;157(4):1145-1150.

9. Haskell WL, Lee IM, Pate RR, Powell KE, Blair SN, Franklin BA, et al. Physical activity and public health: updated recommendation for adults from the American College of Sports Medicine and the American Heart Association. Circulation 2007;116(9):1081-1093.

10. Pate RR, Pratt M, Blair SN, Haskell WL, Macera CA, Bouchard C, et al. Physical activity and public health: a recommendation of the Centers for Disease Control and Prevention and the American College of Sports Medicine. JAMA 1995;273(5):402-407.

11. Lannefors L, Button BM, McIlwaine M. Physiotherapy in infants and young children with cystic fibrosis: current practice and future developments. J R Soc Med 2004;97(Suppl 44):8-25. 


\section{Physical Activity for Children and Adolescents With CF}

12. Bradley J, McAlister O, Elborn S. Pulmonary function, inflammation, exercise capacity and quality of life in cystic fibrosis. Eur Respir J 2001;17(4):712-715.

13. Orenstein DM, Winnie GB, Altman H. Cystic fibrosis: a 2002 update. J Pediatr 2002;140(2):156-164.

14. Klijn PH, Oudshoorn A, van der Ent CK, van der Net J, Kimpen JL, Helders PJ. Effects of anaerobic training in children with cystic fibrosis. Chest 2004;125(4):1299-1305.

15. Pereira CA, Sato T, Rodrigues SC. New reference values for forced spirometry in white adults in Brazil. J Bras Pneumol 2007;33(4): 397-406.

16. de Onis M, Onyango AW, Borghi E, Siyam A, Nishida C, Siekmann J. Development of a WHO growth reference for schoolaged children and adolescents. Bull World Health Organ 2007; 85(9):660-667.
17. Frisancho AR. Anthropometric standards for the assessment of growth and nutritional status. Ann Arbor, MI: University of Michigan Press; 1990.

18. Rozov T, Cunha MT, Nascimento O, Quittner AL, Jardim JR. Linguistic validation of cystic fibrosis quality of life questionnaires. J Pediatr (Rio J) 2006;82(2):151-156.

19. American College of Sports Medicine. Manual da ACMS para o teste de esforço e prescrição do exercício, 5th edition. Rio de Janeiro: Revinter; 2000.

20. Hebestreit H, Kieser S, Junge S, Ballmann M, Hebestreit A, Schindler C, et al. Long-term effects of a partially supervised conditioning programme in cystic fibrosis. Eur Respir J 2010;35(3):578-583.

21. Swisher AK, Erickson M. Perceptions of physical activity in a group of adolescents with cystic fibrosis. Cardiopulm Phys Ther J 2008; 19(4):107-113. 